\title{
Supportive care needs of patients with advanced disease undergoing radiotherapy for symptom control
}

by Margaret I. Fitch

\begin{abstract}
Many patients with advanced cancer have numerous medical complications and multiple sites involving metastases that cause distressing symptoms. Radiotherapy is often used for the palliative treatment of these patients, especially those with bone metastases. There is a lack of information about the types of supportive care needs these patients experience, the services that are available for them, and whether people want help with their needs.

The main purpose of this cross-sectional, descriptive study was to identify the supportive care needs (physical, emotional, social, spiritual, psychological, and practical) of patients with advanced cancer who attended the Palliative Radiation Therapy Rapid Response Clinic (PRTRRC) at a comprehensive, ambulatory cancer centre. A second purpose was to determine if patients wanted assistance in meeting those needs.

A total of 69 patients participated in this study by completing a self-report questionnaire. The data provided a clear indication that a range of supportive care needs remained unmet for this patient group. Lack of energy, pain, and concerns about the worries of those close to them were the most frequently reported needs. Additionally, patients expressed a range of difficulty managing needs and many of these patients desired help to manage the identified needs. However, despite this reality, significant numbers of patients indicated they did not wish to have assistance with some needs. Suggestions for practice and future research are offered to assist oncology nurses in providing supportive care to these patients.
\end{abstract}

Many patients with advanced cancer have numerous medical complications and multiple sites involving metastases that cause distressing symptoms (Andersson \& Sousa, 1998). Radiotherapy is often used for the palliative treatment of these patients (Ciezki, Komurcu, \& Macklis, 2000; Kirkbride, 1995). Patients with bone metastases, in particular, may suffer from pain and impaired mobility (Body, 1992) that may be relieved with a single radiotherapy treatment. However, many patients require a short course of treatment (i.e., several fractions) to achieve pain relief. The Palliative Radiation Therapy Rapid Response Clinic (PRTRRC) was initiated at a comprehensive, ambulatory cancer centre to provide quick access to short-term radiotherapy for patients with symptoms associated with advanced cancer and improve their quality of life (Andersson \& Sousa, 1998). These patients come to the cancer centre for radiation treatment, sometimes only on a single occasion, and return to their home area or hospital for follow-up care. Most patients are assessed by the radiation oncologist, oncology nurse and radiation therapist; undergo planning and simulation; and receive radiation treatment on the same day.

\section{About the authors}

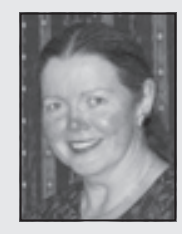

Margaret I. Fitch, RN, PhD, Head, Oncology Nursing, Co-director, Patient and Family Support, Sunnybrook Odette Cancer Centre, 2075 Bayview Avenue, T-wing, Toronto, ON M4N 3M5.

Telephone: 416-480-5891; Fax: 416-480-7806;

Email: marg.fitch@sunnybrook.ca
Health care professionals caring for patients with advanced cancer in our ambulatory centre, in particular the nursing staff, had expressed concern over whether or not the cancer centre was providing a standard of care that met the needs of this population. Moreover, they identified a lack of information about the types of supportive care needs these patients experience, the services that are available for them, whether people want help with their needs, and who, if anyone, is addressing the needs. In response to these concerns, a systematic exploration of the supportive care needs of patients with advanced cancer was undertaken. Our ultimate goal was to optimize the quality of care provided to these patients at the cancer centre. The PRTRRC was chosen as the first site for investigation because all of the patients were categorized as having advanced cancer.

\section{Literature review}

Cancer and its treatment have physical, social, emotional, psychological, spiritual, and practical consequences for individuals who are living with cancer (Ashbury, Findley, Reynolds, \& McKerracher, 1998; Charles, Sellick, Montesanto, \& Mohide, 1996; Fitch, Porter, \& Page, 2008; Whelan et al., 1997). As the disease progresses and symptoms become more pronounced, patients and family members may experience difficulties in managing daily activities and in coping with the situation. Many patients with advanced cancer are polysymptomatic. Physical symptoms such as fatigue (Bradley, Davis, \& Chow, 2005), pain (Bradley et al., 2005; Bruera et al., 2001), anorexia (Hutton et al., 2006; Sarna, Lindsey, Dean, Brecht, \& McCorkle, 1994), coughing (Sarna et al., 2004), poor sense of well-being (Bradley et al.; Bruera et al., 2001), and breathlessness (Bradley et al., 2005; Edmonds, Karlsen, Khan, \& Addington-Hall, 2001) are common and negatively impact the lives of patients and family members dealing with advanced cancer. In a review article, Solano and Higginson (2006) analyzed 33 articles that reported the prevalence for 11 symptoms in advanced cancer patients (sample sizes ranged from 2,888 to 10,379 patients for each symptom). While there was a wide range in the reported prevalence across studies, pain, fatigue and breathlessness were generally found among more than 50\% of patients with advanced cancer.

Other symptoms such as depression and anxiety (Bradley et al., 2005; Bruera et al., 2001) are frequently present as well, and have a detrimental effect on patients' quality of life. Bradley and colleagues (2005) reported that $61 \%$ of patients attending their clinic suffered from depression $(n=1,070)$. Depression was moderate to severe in $30 \%$ of these patients. In addition, $78 \%$ reported anxiety $(\mathrm{n}=1,079)$, with 121 patients $(11 \%)$ exhibiting severe levels. Solano and Higginson (2006) also noted high levels of anxiety and depression in their review of patients with advanced cancer (sample sizes of 3,274 and 4,378 patients respectively).

While some information is known about the supportive care needs of patients with advanced cancer, there is a paucity of knowledge about the full range of needs for palliative outpatients, which needs remain unmet, and whether patients want help with their unmet needs. Such information is important for several reasons: 1) to plan a patient's individual care, 2) to make decisions about resource allocation, and 3) to identify potential areas for improving the quality of care delivery. 


\section{Purpose}

The main purpose of this cross-sectional, descriptive study was to identify the supportive care needs (physical, emotional, social, spiritual, psychological, and practical) of patients with advanced cancer who attended the Palliative Radiation Therapy Rapid Response Clinic (PRTRRC) at a comprehensive, ambulatory cancer centre. A second purpose was to determine if patients were experiencing unmet needs and wanted assistance in meeting those needs.

\section{Method}

\section{Procedures-Recruitment and data collection}

The study commenced once ethical approval had been received from the Sunnybrook Research Ethics Committee. A research associate (RA) consulted with staff in the PRTRRC to identify potential participants. Any patients attending the PRTRRC were considered eligible for participation in this study unless they were acutely distressed and unable to focus on completing the questionnaire. This study was composed of a convenience sample of patients with a range of cancer diagnoses who were medically diagnosed with advanced cancer. Eligible patients were approached in the reception area of the clinic by the RA who explained the study objectives and methods. Verbal information was given to ensure the patient was aware of his or her rights regarding participation and the RA then invited the patient to participate. Those who agreed to participate signed a consent form in duplicate. The patient kept one copy and the RA retained the other.

The RA gave each participating patient a self-report questionnaire to complete and assessed if the patient required assistance to complete the form. If patients required assistance due to physical disability, the RA took the patient to a private area and completed the questionnaire through an interview format. For those patients who agreed to complete the questionnaire by themselves during their clinic visit, the RA checked back with the patient at a specified time to collect the completed questionnaire. There was also a box in the clinic for patients to leave completed questionnaires in a sealed envelope. The questionnaire took between 15 to 20 minutes to complete. Finally, if a patient was unable to complete the questionnaire during his/her clinic visit, the RA provided a pre-stamped, addressed business reply envelope in which to return the questionnaire. Returning the completed questionnaire was left up to the individual and no reminders were sent.

The measurement tool (see description below) was only available in English. Therefore, to minimize exclusion of patients who did not speak, read, and/or write English, accompanying family or friends who were fluent in the English language were invited to explain the study to those patients and provide translation if they and the patient both agreed. The patient signed the consent form and the translator also signed and made a notation that the patient's consent was voluntary. The RA kept track of how the questionnaires

Table 1. Supportive Care Needs Survey (SCNS, 61 items)

\begin{tabular}{|l|c|c|}
\hline Domain & Number of items & $\begin{array}{c}\text { Cronbach's alpha } \\
\text { coefficients }\end{array}$ \\
\hline Informational & 9 & 0.81 \\
\hline Physical symptoms & 11 & 0.78 \\
\hline Psychological & 11 & 0.74 \\
\hline Emotional & 11 & 0.72 \\
\hline Spiritual & 7 & 0.71 \\
\hline Social & 5 & 0.43 \\
\hline Practical & 7 & 0.35 \\
\hline
\end{tabular}

were completed (by the patient directly, through an interview format with the RA, or through an interpreter). There were no differences in response rates noted between these groups in the analysis. When the patient gave permission in the consent form, the RA also accessed patients' charts to complete the demographic form and to note when metastases were first diagnosed in patients.

\section{Data collection instrument}

The questionnaire used in this study consisted of two parts. The demographic component was created for the purposes of this study, while the supportive care needs assessment was an adaptation of a tool from Bonevski et al. (2000).

The demographic form had eight questions: age in years; gender; marital status; highest level of education completed; type of cancer; month and year when cancer was first diagnosed; treatment received for the cancer; and treatment currently being given for the cancer. The Supportive Care Needs Survey formed the basis of the questionnaire used in this study. The Supportive Care Needs Survey was originally developed and validated in Australia (Bonevski et al. 2000). A principal components factor analysis revealed the needs items grouped under five factors, which were physical and daily living, psychological, health system and information, patient care and support, and sexuality. The Cronbach's alpha coefficients for these factors or subscales ranged from 0.87 to 0.97 . The original tool contained 60 close-ended items. Patients responded to a fivepoint Likert Scale for each item where "0" was "no need" (i.e., item is not an issue for the patient as a result of having cancer) to " 4 " reflecting a "high need" for help (i.e., the item is of major concern or importance to the patient and the person has a strong need for additional help with the problem or concern). The tool can be readily comprehended by individuals with minimal education and completed in about 20 minutes (Bonevski et al., 2000).

The current study employed the revised version (Supportive Care Needs Survey-Radiation) of the original Supportive Care Needs Survey (Bonevski et. al., 2000). A pilot test of Bonevski's original tool had been conducted with lung cancer patients in our Canadian cancer centre and resulted in the reordering of some items to improve clarity and slight word changes to reflect the Canadian ambulatory setting. For example, "hospital" was changed to "cancer centre." The revised version of the tool also included an additional question after each item about the patient's desire for help for that particular need. For each item, patients were asked to indicate if they wished to have help in dealing with the specific need (i.e., No, I do not want any help; Yes, I would like help; I feel uncertain about wanting help). The Revised Supportive Care Needs Survey was composed of seven domains of supportive care over 61 items (see Table $1)$. Reliability results for the lung cancer group were reported as 0.66 to 0.90 , with six of the seven domain subscales being 0.80 or higher (Fitch \& Steele, 2010b). The Cronbach's alpha coefficients for the seven domain subscales in this study ranged from 0.35 (practical) to 0.81 (informational) (see Table 1). There were no significant differences on the supportive needs subscales except where women had slightly higher mean scores than men $(t=2.0157, p=0.0478)$ on the practical subscale. Hence, results are reported for the combined group.

\section{Data analysis}

Analysis of the supportive care needs data was descriptive and focused on our calculation of item frequency and subscale mean scores and standard deviations. Tests of difference were used to determine the influence of selected demographic variables on the level of expressed need (t-tests for gender and education level; ANOVA for the categorical variables marital status, time since diagnosis, and age). Significance level was set at $\mathrm{p}<0.05$ for all tests and the SPSS statistical program was utilized for the analysis. 


\section{Results}

\section{Sample}

One hundred and six patients $(\mathrm{n}=106)$ were approached in the waiting room over a period of nine months and 95 of them agreed to participate in the study. Eleven patients verbally declined participation when approached by the RA because they did not want to participate in a research study, they did not feel "up to it," or they indicated they might be interested at another time. Another two patients did not provide a reason to the RA. Of the 93 surveys handed out, some were not returned via mail, three individuals were not actually eligible upon review (not Rapid Response Radiation Program [RRRP] patients), and some surveys were missing data for four or more items and were considered unusable. The final sample size was 69 patients.

There were almost equal numbers of men and women in the sample (see Table 2). Similar to the clinic population, the sample was older with an average age of 65 years, most patients were married $(\mathrm{n}=52)$, and almost one-quarter had at least a college-level education. Approximately $45 \%$ had been diagnosed for less than a year. Patients presented with a variety of types of cancers, such as breast, gastrointestinal, prostate, and lung. About 75\% reported they were currently on treatment. All reported receiving chemotherapy, radiotherapy, surgery, or a combination of these treatments in the past.

\section{Most frequently reported issues currently experienced}

Patients reported that they were currently experiencing supportive care needs across all seven domains and for almost all items. The number of patients experiencing a specific issue ranged from zero (e.g., physical needs, "hospital staff to attend promptly to your physical needs"; social needs, "family and friends to be allowed with you in hospital whenever you want") to 53 (e.g., physical needs, "lack of energy"). The informational domain was the only domain without at least one item where a quarter or more of the patients were currently experiencing an issue in this domain. Tables 3 through 9 present the data for each domain.

Eleven issues were reported as being currently experienced by more than $50 \%$ of the patients. Six issues were from the physical domain (i.e., lack of energy, pain, not being able to do things you used to do, not being able to work around the home, feeling unwell, and decreased appetite); three were psychological (i.e., fears about physical disability or deterioration, fears about cancer spreading, and fears about pain); one was social (i.e., concerns about the worries of those close to you); and one, emotional (i.e., feeling down or depressed) (see Table 10).

\section{Desire for help}

Patients who reported currently experiencing an issue were asked to also indicate if they wished to have help in dealing with the need. The assumption was made that anyone who was "uncertain" about wanting help warranted a conversation with staff. Therefore, we combined the number of patients who reported "uncertain" with the number of patients who said "yes" to wanting help. This total was divided by the number of participants who reported currently experiencing the issue. These calculations determined the percentages of people currently experiencing an issue who desired some type of help. Results from those who reported either "yes" or "uncertain" are presented in Tables 3 to 9. The range in percentages of patients with an issue who may have desired help with it, varied across the domains: psychological $28.6 \%$ to $100 \%$; practical $28 \%$ to $100 \%$; emotional $23.5 \%$ to $100 \%$; informational $50 \%$ to $85.7 \%$; physical $33.3 \%$ to $63.5 \%$; spiritual $25 \%$ to $55.6 \%$; and social $29 \%$ to $45.5 \%$. However, it should be noted this is a small sample and the absolute numbers of individuals wanting help were small (see Table 10).

\begin{tabular}{|c|c|}
\hline Variable & Finding (n, \%) \\
\hline Gender & $\begin{array}{l}\text { Male }=35(50.7 \%) \\
\text { Female }=34(49.3 \%)\end{array}$ \\
\hline Age & $\begin{array}{l}\text { Mean }=65 \text { years } \\
\text { Range }=35-84 \text { years }\end{array}$ \\
\hline Marital status & $\begin{array}{l}\text { Married }=52(75.4 \%) \\
\text { Separated/Divorced/Widowed }=15(21.7 \%) \\
\text { Single }(\text { never married })=2(2.9 \%)\end{array}$ \\
\hline Education level & $\begin{array}{l}<\text { College }=52(75.4 \%) \\
\geq \text { College }=17(24.6 \%)\end{array}$ \\
\hline $\begin{array}{l}\text { Length of time } \\
\text { since diagnosis }\end{array}$ & $\begin{array}{l}<1 \text { Year }=31(45.6 \%) \\
1-2 \text { Years }=9(13.2 \%) \\
2+\text { Years }=28(41.2 \%)\end{array}$ \\
\hline \multicolumn{2}{|c|}{$\begin{array}{l}\text { * missing data in some cases mean numbers do not always add up } \\
\text { to } 69\end{array}$} \\
\hline
\end{tabular}

\section{Table 3. Informational needs $(n=69)$}

\begin{tabular}{|c|c|c|c|c|}
\hline Issue & $\begin{array}{l}\text { Number } \\
\text { of patients } \\
\text { currently } \\
\text { experiencing } \\
\text { issue }\end{array}$ & \begin{tabular}{|l|} 
Number \\
of \\
patients \\
who want \\
help
\end{tabular} & $\begin{array}{l}\text { Number } \\
\text { of patients } \\
\text { uncertain } \\
\text { if they } \\
\text { want help }\end{array}$ & $\begin{array}{l}\text { Proportion who } \\
\text { want help or } \\
\text { are uncertain } \\
\text { of those } \\
\text { experiencing } \\
\text { issue } n / \% *\end{array}$ \\
\hline $\begin{array}{l}\text { To be given information about aspects of managing your illness and side effects } \\
\text { of treatment }\end{array}$ & 16 & 11 & 1 & $12 / 75 \%$ \\
\hline To be informed about test results as soon as possible & 14 & 8 & 1 & $9 / 64.3 \%$ \\
\hline To be given written information about important aspects of your care & 13 & 8 & 0 & $8 / 61.5 \%$ \\
\hline To be informed about the things you can do to help yourself get well & 10 & 8 & 0 & $8 / 80 \%$ \\
\hline To be informed about cancer that is under control or diminishing (in remission) & 8 & 5 & 1 & $6 / 75 \%$ \\
\hline To be adequately informed about the benefits and side effects of treatment & 8 & 4 & 1 & $5 / 62.5 \%$ \\
\hline To be given explanations of those tests for which you would like explanations & 8 & 4 & 0 & $4 / 50 \%$ \\
\hline To be informed about support groups in your area & 7 & 5 & 1 & $6 / 85.7 \%$ \\
\hline To be given information about sexual relationships & 4 & 3 & 0 & $3 / 75 \%$ \\
\hline
\end{tabular}




\section{Discussion}

This study was undertaken to explore the supportive care needs of patients living with advanced cancer who were attending a radiotherapy clinic for symptom control. The study provides a picture of the range of physical and psychosocial needs these patients were experiencing, as well as an indication of the degree to which their needs remained unmet and whether they wanted assistance with these unmet needs.

Symptoms previously identified in the literature were also present for the patients who participated in this study. Despite the wide range of prevalence in symptoms across studies, pain, fatigue, and breathlessness were generally found among more than $50 \%$ of patients with advanced cancer (Solano \& Higginson, 2006). In this study, fatigue (lack of energy) (76.8\%) and pain (75.4\%) were the most frequently reported issues experienced by patients at the PRTRRC, and 32 of the 69 (46.4\%) patients reported shortness of breath.

Other previously identified symptoms that were reported by more than $50 \%$ of patients in the current study included anorexia (Hutton et al., 2006), poor sense of well-being (Bruera et al., 2001; Bradley et al., 2005), and depression (Bruera et al., 2001; Bradley et al., 2005; Solano \& Higginson, 2006). Although not in the top issues reported in this study, common symptoms that have been reported in the literature also were found in this sample including coughing (Sarna et al., 2004), and anxiety (Bruera et al., 2001; Bradley et al., 2005; Solano \& Higginson, 2006).

Interestingly, just because a high number of patients were currently experiencing an issue, this did not necessarily mean the same patients wanted help. Even with the most frequently experienced

continued on page $89 \ldots$

\begin{tabular}{|c|c|c|c|c|}
\hline Issue & \begin{tabular}{|l|} 
Number of \\
patients currently \\
experiencing \\
issue
\end{tabular} & $\begin{array}{l}\text { Number of } \\
\text { patients who } \\
\text { want help }\end{array}$ & $\begin{array}{l}\text { Number } \\
\text { of patients } \\
\text { uncertain if } \\
\text { they want help }\end{array}$ & $\begin{array}{l}\text { Proportion who want } \\
\text { help or are uncertain } \\
\text { of those experiencing } \\
\text { issue } n / \% *\end{array}$ \\
\hline Lack of energy & 53 & 24 & 4 & $28 / 52.8 \%$ \\
\hline Pain & 52 & 31 & 2 & $33 / 63.5 \% \%$ \\
\hline Not being able to do things you used to & 49 & 20 & 3 & $23 / 46.9 \%$ \\
\hline Not being able to work around at home & 43 & 17 & 2 & $19 / 44.2 \%$ \\
\hline Feeling unwell & 38 & 13 & 4 & $17 / 44.7 \%$ \\
\hline Decreased appetite & 38 & 15 & 3 & $18 / 47.4 \%$ \\
\hline Shortness of breath & 32 & 12 & 2 & $14 / 43.8 \%$ \\
\hline Coughing & 21 & 6 & 4 & $10 / 47.6 \%$ \\
\hline Nausea/Vomiting & 20 & 8 & 0 & $8 / 40 \%$ \\
\hline Changes in sexual feelings & 12 & 4 & 0 & $4 / 33.3 \%$ \\
\hline Hospital staff to attend promptly to your physical needs & 0 & 0 & 0 & $\mathrm{~N} / \mathrm{A}$ \\
\hline
\end{tabular}

Table 5. Emotional needs $(n=69)$

\begin{tabular}{|c|c|c|c|c|}
\hline Issue & $\begin{array}{l}\text { Number } \\
\text { of patients } \\
\text { currently } \\
\text { experiencing } \\
\text { issue }\end{array}$ & $\begin{array}{l}\text { Number of } \\
\text { patients who } \\
\text { want help }\end{array}$ & $\begin{array}{l}\text { Number } \\
\text { of patients } \\
\text { uncertain if } \\
\text { they want } \\
\text { help }\end{array}$ & $\begin{array}{l}\text { Proportion who } \\
\text { want help or are } \\
\text { uncertain of those } \\
\text { experiencing issue } \\
n / \% *\end{array}$ \\
\hline Feeling down or depressed & 40 & 10 & 2 & $12 / 30 \%$ \\
\hline Feelings of sadness & 34 & 4 & 4 & $8 / 23.5 \%$ \\
\hline Feeling bored and/or useless & 34 & 7 & 4 & $11 / 32.4 \%$ \\
\hline Anxiety & 34 & 6 & 6 & $12 / 35.3 \%$ \\
\hline Worry that the results of your treatment are beyond your control & 25 & 9 & 3 & $12 / 48 \%$ \\
\hline Anxiety about having any treatment & 24 & 11 & 1 & $12 / 50 \%$ \\
\hline Changes in sexual relationships & 16 & 3 & 4 & $7 / 43.8 \%$ \\
\hline $\begin{array}{l}\text { The opportunity to talk with someone who understands and has } \\
\text { been through similar experience }\end{array}$ & 8 & 5 & 0 & $5 / 62.5 \%$ \\
\hline To have one member of hospital staff with whom you can talk & 6 & 2 & 2 & $4 / 66.7 \%$ \\
\hline To be treated like a person, not just another case & 6 & 2 & 1 & $3 / 50 \%$ \\
\hline Hospital staff to acknowledge and show sensitivity to your feelings & 2 & 1 & 1 & $2 / 100 \%$ \\
\hline
\end{tabular}


Table 6. Psychological needs $(n=69)$

\begin{tabular}{|c|c|c|c|c|}
\hline Issue & $\begin{array}{l}\text { Number } \\
\text { of patients } \\
\text { currently } \\
\text { experiencing } \\
\text { issue }\end{array}$ & $\begin{array}{l}\text { Number } \\
\text { of patients } \\
\text { who want } \\
\text { help }\end{array}$ & $\begin{array}{l}\text { Number } \\
\text { of patients } \\
\text { uncertain if } \\
\text { they want } \\
\text { help }\end{array}$ & $\begin{array}{l}\text { Proportion who } \\
\text { want help or are } \\
\text { uncertain of those } \\
\text { experiencing issue } \\
\mathbf{n} / \%^{*}\end{array}$ \\
\hline Fears about physical disability or deterioration & 42 & 17 & 4 & $21 / 50 \%$ \\
\hline Fears about cancer spreading & 35 & 15 & 3 & $18 / 51.4 \%$ \\
\hline Fears about pain & 35 & 19 & 3 & $22 / 62.9 \%$ \\
\hline Fears about losing your independence & 29 & 11 & 2 & $13 / 44.8 \%$ \\
\hline Accepting changes in your physical appearance & 17 & 7 & 1 & $8 / 47.1 \%$ \\
\hline Fears about cancer returning & 14 & 7 & 3 & $10 / 71.4 \%$ \\
\hline Learning to feel in control of your situation & 14 & 3 & 1 & $4 / 28.6 \%$ \\
\hline To have access to professional counselling if you or your family need it & 5 & 4 & 0 & $4 / 80 \%$ \\
\hline Reassurance by the medical staff that the way you feel is normal & 4 & 2 & 1 & $3 / 75 \%$ \\
\hline To be treated in a hospital or clinic that is pleasant & 3 & 1 & 0 & $1 / 33.3 \%$ \\
\hline More fully protected rights to privacy when you are at the hospital & 2 & 1 & 1 & $2 / 100 \%$ \\
\hline
\end{tabular}

Table 7. Spiritual needs $(n=69)$

\begin{tabular}{|c|c|c|c|c|}
\hline Issue & $\begin{array}{l}\text { Number of } \\
\text { patients currently } \\
\text { experiencing issue }\end{array}$ & $\begin{array}{l}\text { Number of } \\
\text { patients who } \\
\text { want help }\end{array}$ & $\begin{array}{l}\text { Number of patients } \\
\text { uncertain if they } \\
\text { want help }\end{array}$ & $\begin{array}{l}\text { Proportion who want help } \\
\text { or are uncertain of those } \\
\text { experiencing issue } n / \%^{*}\end{array}$ \\
\hline Uncertainty about the future & 29 & 9 & 4 & $13 / 44.8 \%$ \\
\hline Feelings about death and dying & 22 & 6 & 1 & $7 / 31.8 \%$ \\
\hline Confusion about why this has happened to you & 22 & 9 & 0 & $9 / 40.9 \%$ \\
\hline Finding meaning in this experience & 13 & 3 & 1 & $4 / 30.8 \%$ \\
\hline Making the most of your time & 12 & 3 & 0 & $3 / 25 \%$ \\
\hline Keeping a positive outlook & 9 & 5 & 0 & $5 / 55.6 \%$ \\
\hline Hospital staff to convey a sense of hope & 2 & 1 & 0 & $1 / 50 \%$ \\
\hline
\end{tabular}

Table 8. Social needs $(n=69)$

\begin{tabular}{|c|c|c|c|c|}
\hline Issue & $\begin{array}{l}\text { Number } \\
\text { of patients } \\
\text { currently } \\
\text { experiencing } \\
\text { issue }\end{array}$ & $\begin{array}{l}\text { Number } \\
\text { of patients } \\
\text { who want } \\
\text { help }\end{array}$ & $\begin{array}{l}\text { Number } \\
\text { of patients } \\
\text { uncertain } \\
\text { if they } \\
\text { want help }\end{array}$ & $\begin{array}{l}\text { Proportion who } \\
\text { want help or } \\
\text { are uncertain } \\
\text { of those } \\
\text { experiencing } \\
\text { issue } n / \% *\end{array}$ \\
\hline Concerns about the worries of those close to you & 51 & 12 & 3 & $15 / 29.40 \%$ \\
\hline Concerns about the ability of those close to you to cope with caring for you & 31 & 7 & 2 & $9 / 29 \%$ \\
\hline Talking to other people about the cancer & 11 & 4 & 1 & $5 / 45.5 \%$ \\
\hline Changes in people's attitudes and behaviours towards you & 9 & 3 & 0 & $3 / 33.30 \%$ \\
\hline Family and friends to be allowed with you in hospital whenever you want & 0 & 0 & 0 & $\mathrm{~N} / \mathrm{A}$ \\
\hline
\end{tabular}




\begin{tabular}{|c|c|c|c|c|}
\hline \multicolumn{5}{|l|}{ Table 9. Practical needs $(n=69)$} \\
\hline Issue & $\begin{array}{l}\text { Number } \\
\text { of patients } \\
\text { currently } \\
\text { experiencing } \\
\text { issue }\end{array}$ & $\begin{array}{l}\text { Number } \\
\text { of patients } \\
\text { who want } \\
\text { help }\end{array}$ & $\begin{array}{l}\text { Number } \\
\text { of patients } \\
\text { uncertain if they } \\
\text { want help }\end{array}$ & $\begin{array}{l}\text { Proportion who } \\
\text { want help or are } \\
\text { uncertain of those } \\
\text { experiencing issue } \\
\text { n/\%* }\end{array}$ \\
\hline Changes in usual routine and lifestyle & 25 & 7 & 0 & $7 / 28 \%$ \\
\hline Waiting a long time for clinic appointments & 13 & 8 & 1 & $9 / 69.2 \%$ \\
\hline Concerns about your financial situation & 13 & 7 & 0 & $7 / 53.8 \%$ \\
\hline Concerns about getting to and from the hospital & 12 & 8 & 1 & $9 / 75 \%$ \\
\hline More choice about which hospital you attend & 9 & 2 & 1 & $3 / 33.3 \%$ \\
\hline To be given choices about when you go for tests or treatments & 6 & 2 & 1 & $3 / 50 \%$ \\
\hline More choice about the cancer specialist you see & 4 & 3 & 1 & $4 / 100 \%$ \\
\hline
\end{tabular}

Table 10. Currently experienced issues reported by $>50 \%$ patients $(n=69)$

\begin{tabular}{|c|c|c|c|c|}
\hline Issue & $\begin{array}{l}\text { Number of } \\
\text { patients currently } \\
\text { experiencing issue }\end{array}$ & $\begin{array}{l}\text { Number of } \\
\text { patients who } \\
\text { want help }\end{array}$ & $\begin{array}{l}\text { Number of } \\
\text { patients uncertain } \\
\text { if they want help }\end{array}$ & $\begin{array}{l}\text { Proportion who want } \\
\text { help or are uncertain } \\
\text { of those experiencing } \\
\text { issue } n / \% *\end{array}$ \\
\hline Lack of energy $(\mathrm{PH})$ & 53 & 24 & 4 & $28 / 52.8 \%$ \\
\hline Pain $(\mathrm{PH})$ & 52 & 31 & 2 & $33 / 63.5 \%$ \\
\hline Concerns about the worries of those close to you (SO) & 51 & 12 & 3 & $15 / 29.4 \%$ \\
\hline Not being able to do things you used to $(\mathrm{PH})$ & 49 & 20 & 3 & $23 / 46.9 \%$ \\
\hline Not being able to work around at home (PH) & 43 & 17 & 2 & $19 / 44.2 \%$ \\
\hline Fears about physical disability or deterioration (PS) & 42 & 17 & 4 & $21 / 50 \%$ \\
\hline Feeling down or depressed (E) & 40 & 10 & 2 & $12 / 30 \%$ \\
\hline Feeling unwell (PH) & 38 & 13 & 4 & $17 / 44.7 \%$ \\
\hline Decreased appetite (PH) & 38 & 15 & 3 & $18 / 47.4 \%$ \\
\hline Fears about cancer spreading (PS) & 35 & 15 & 3 & $18 / 51.4 \%$ \\
\hline Fears about pain (PS) & 35 & 19 & 3 & $22 / 62.9 \%$ \\
\hline
\end{tabular}

11 items, only $29.4 \%$ to $63.5 \%$ of patients currently experiencing an issue wanted help with it. In contrast, even though relatively few people were experiencing an issue in some cases, a high proportion of those with the need wanted help with it. For example, although informational needs were not in the top 11 issues, $50 \%$ to $85.7 \%$ of patients who had needs in this domain wanted help.

Similar results about patients' desire for help have been found with other populations, with varying stages of cancer, at this cancer clinic (Fitch \& Steele, 2010a; Fitch \& Steele, 2010b; Steele et al., 2004; Steele \& Fitch, 2008) and elicited questions from staff members about whether patients actually know what they require. However, a qualitative study with 34 patients at the centre revealed there are multiple reasons why patients stated they did not want help from the staff at a particular point in time. Examples of these reasons included believing the staff was too busy, the staff would not be interested in a certain type of problem, the problem would go away over time, or there was nothing that could be done for the type of problem the individual was experiencing (Steele \& Fitch, 2008). Participants in Steele and Fitch's study also identified a number of outside or community-based resources they had used instead of the cancer centre, such as family, friends, and community professionals.

\section{Implications}

For practice: Symptoms

As with previous studies (e.g., Bradley et al., 2005), the lack of energy was a major issue for a large number of advanced stage cancer patients. Overwhelming fatigue affects a person's ability to carry out normal everyday activities (Fitch, Mings, \& Lee, 2008) and the effect of the associated losses can be devastating to a person's well-being (Kennett \& Payne, 2005). Yet, there is research evidence available about how to deal with fatigue. Oncology nurses need to provide patients with suggestions for managing lack of energy that could lead to enhanced quality of life for these patients (Fitch, Mings, \& Lee, 2008).

Pain was also a significant issue that has been found in previous studies (Bradley et al., 2005; Bruera et al., 2001). Given the nature of the PRTRRC, it is perhaps not surprising that so many patients presented with pain. However, the extent of this issue makes a strong case for more effective pain control. While it can be difficult to follow up and assess effectiveness in this patient population, as many only receive a single treatment at the cancer centre, it is important to engage in follow-up to ensure optimal care is delivered. Cancer 
centres may want to consider the use of a telephone follow-up service for their palliative patients to assess symptom palliation, rather than expecting patients to return to clinic for assessment (Chow et al., 2001).

The symptoms of depression and anxiety were also prevalent issues in this study and ones for which patients wanted assistance. Previous evidence has shown these symptoms can have a detrimental effect on patients' quality of life (Bruera et al., 2001; Bradley et al., 2005). These symptoms must also be assessed and documented in order to enhance referrals for appropriate management (Bradley et al., 2005). Bruera et al. (2001) demonstrated that patients in their clinic $(n=166)$ obtained statistically significant psychosocial improvement when they received assistance from a multi-professional team. Centres may need to expand their professional resources or re-evaluate the ways in which they currently provide care to ensure patients received the most appropriate assistance.

\section{For practice: Psychosocial concerns}

Psychosocial issues (i.e., psychological, social, and emotional domain items) were among the most frequently reported issues that patients were experiencing at the time of the survey. These have also been previously identified in the literature (e.g., Bradley et al., 2005; Bruera et al., 2001; Kennett \& Payne, 2005; Solano \& Higginson, 2006). There is growing breadth of evidence that psychosocial intervention may improve well-being and survival for patients with cancer (Chow, Tsao, \& Harth, 2004) and well-being for palliative patients (Kennett \& Payne, 2005). For example, Voogt et al. (2005) suggested that mood disorders in patients with advanced cancer ( $\mathrm{n}=105)$ may be related to the absence of positive feelings rather than to a high level of negative feelings. A lack of positive emotions was linked to an inability to engage in meaningful activities and a reduction in cognitive and social functioning, as well as to more fatigue. If professionals can uncover what activities are meaningful to patients and help them continue them for as long as possible or suggest substitute activities when needed, then patients may suffer less psychological distress. Additionally, there is a growing recognition that we need to understand more about symptom clusters and how our interventions may have an effect on several symptoms (Fitch \& Bultz, 2009).

\section{For practice: Providing help when desired}

A method of effectively and efficiently assessing the supportive care needs of all patients with advanced cancer on a routine basis should be developed. The most frequently identified issues from this study could be used as items for a screening or triage tool that would identify the issues currently experienced, the extent to which they are being experienced, and whether or not a patient wants help with the issue. This preliminary triage step could be the basis for a conversation with the patient which, in turn, could lead to a deeper assessment of issues concerning the individual. An exploration of patient expectations regarding assistance would then enable oncology nurses and patients to discuss the next steps that would ensure the patients receive the kind of help they want.

The instrument used in the current study provided the necessary type of comprehensive assessment of needs across the spectrum of supportive care. Uncovering issues affords professionals the opportunity to provide assistance. However, professionals should not make assumptions that if an issue is not brought up by a patient then it is not an issue for that person. Nor should they assume that because only a few people may have an issue that it is not really important to discuss. It is important to ask patients if they have an issue and if they want help with it. Although a significant number of people do want help with issues, there are some who do not and patients' wishes should be honoured. A discussion with patients could lead to a shared understanding between patient and provider about what would be most helpful from the patient's perspective. Health care providers need to acknowledge psychological issues, such as fears about physical disability or deterioration, as well as physical issues and ensure open dialogue and communication with patients so they can direct people to appropriate resources for help.

\section{For resources and policy}

The magnitude of the proportion of patients who indicated they would like help in resolving specific issues suggests that a number of patients were looking for assistance over and above that which was currently being provided to them. Clearly, even in good cancer centres, patients still had unmet needs. This observation has implications for future program planning, resource allocation and research, for both rapid response clinics and other areas of cancer centres where patients with advanced cancer receive care.

Cancer centres do not have the resources to provide all services to all people; yet, they do have a responsibility to patients with advanced cancer. Standards of quality cancer care emphasize that cancer care treatment should be optimal across the spectrum of care. At the same time, cancer centres may feel limited in the resources they can commit to the group of patients with advanced cancer who only attend for one or two treatments. Therefore, planning and resource allocation need to be treated differentially between the short-term and longer-term patients at the centre. In terms of the PRTRRC, staff could identify certain problems in patients who are being assessed and then make those who provide the primary care outside the centre aware of the problems. Where care is shared with community physicians who continue to provide the overall management of palliative care, cancer centre staff could give the patient a letter about his/her treatment and include information about what issues need to be addressed. While this action has the potential to be construed as a directive to primary care physicians, it does help to keep the patients' needs and desire for help at the centre of attention by health care providers across the continuum of patient-oriented care.

It is also imperative that appropriate resources and available interventions are discussed with the patients. Ideally, this discussion would be undertaken as part of standard of care by the oncology nurse. In some areas, centres might employ advanced practice nurses to provide care in the more complex situations. The results from this current study illustrate that issues are present, and standards of care articulate they ought to be dealt with (Accreditation Canada, 2010). Ultimately, these data can provide a basis of support for program funding in supportive care, the identification of interventions and the development of evidence-based protocols.

\section{For research}

A number of research projects are warranted based on this study's novel findings. For example, further investigation of why patients with advanced disease say they do not desire help for certain areas of need, what resources currently exist outside the cancer centre that they use to help meet their needs, and what resources (internal and external to the cancer centre) would be helpful to them. An in-depth literature review could be conducted to explore the top three issues identified in this study (including a dyadic approach that involves family caregivers who care for these patients at home), and develop local interventions for these issues that are tested through a randomized controlled trial to compare standard care against the intervention that is based on the patient's unique needs and desire for help. Patients and family caregivers could be followed in a longitudinal study to identify which interventions were effective, for whom were these interventions effective and mediating mechanisms or processes that help to explain why the intervention(s) worked. Finally, psychosocial improvement could be assessed in clinics that offer assistance from a multi-professional team. 


\section{Conclusion}

Ambulatory care patients with advanced cancer who attended a palliative radiation clinic reported similar symptoms and psychosocial needs to those of other patients with advanced cancer. However, identifying that they were currently experiencing an issue did not necessarily equate with wanting help with that issue. Paradoxically, for some items where relatively few patients were experiencing an issue, a higher percentage of those patients wanted help with it. Oncology nurses must assess unique patients' needs in

\section{REFERENCES}

Accreditation Canada (2010). Standards: Cancer care and oncology services. Ottawa: Author.

Andersson. L., \& Sousa, P. (1998). An innovative way of caring: Palliative radiation therapy rapid response clinic. Canadian Oncology Nursing Journal, 8(2), 146-147.

Ashbury, F.D., Findley, H., Reynolds, B., \& McKerracher, K. (1998). A Canadian survey of cancer patients' experiences: Are their needs being met? Journal of Pain and Symptom Management, 16(5), 298-306.

Body, J. (1992). Metastatic bone cancer: Clinical and therapeutic aspects. Bone, 13, 1350-1354.

Bonevski, B., Sanson-Fisher, R., Girgis, A., Burton, L., Cook, P., Boyes, A., \& the Supportive Care Review Group. (2000). Evaluation of an instrument to assess the needs of patients with cancer. Cancer, 88(1), 217-225.

Bradley, N., Davis, L., \& Chow, E. (2005). Symptom distress in patients attending an outpatient palliative radiotherapy clinic. Journal of Pain and Symptom Management, 30(2), 123-131.

Bruera, E., Michaud, M., Vigano, A., Neumann, C., Watanabe, S., \& Hanson, J. (2001). Multidisciplinary symptom control clinic in a cancer centre: A retrospective study. Support Care Cancer, 9, 162-168.

Charles, K., Sellick, S.M., Montesanto, B., \& Mohide, E.A. (1996). Priorities for cancer survivors regarding psychosocial needs. Journal of Psychosocial Oncology, 14(2), 57-72.

Chow, E., Tsao, M., \& Harth, T. (2004). Does psychosocial intervention improve survival in cancer? A meta-analysis. Palliative Medicine, $18,25-31$.

Chow, E., Wong, R., Connolly, R., Hruby, G., Franssen, E., Fung, K., et al. (2001). Prospective assessment of symptom palliation for patients attending a rapid response radiotherapy program: Feasibility of telephone follow-up. Journal of Pain and Symptom Management, 22(2), 649-656.

Ciezki, J., Komurcu, S., \& Macklis, R. (2000). Palliative radiotherapy. Seminars in Oncology, 27(1), 90-93.

Edmonds, P., Karlsen, S., Khan, S., \& Addington-Hall, J. (2001). A comparison of the palliative care needs of patients dying from chronic respiratory diseases and lung cancer. Palliative Medicine, 15(4), 287-295.

Fitch, M.I., Mings, D., \& Lee, A. (2008). Exploring patient initiated strategies for living with treatment-related fatigue. Canadian Oncology Nursing Journal, 18(3),124-140.

Fitch, M.I., \& Bultz, B. (2009). Symptom patterns in patients with advanced cancer. Oncology Exchange, 8(4),11-13. multiple areas (e.g., physical, psychosocial, spiritual, informational, practical), but they must be aware that some patients do not want help. At a particular point in time, what is important is that nurses and patients enter into a dialogue to determine what is a concern and what assistance for that concern may be available and will be valued from the patient's perspective. Providing a broad range of help may be useful to patients, but clinics need to plan and develop their interventions in a manner that meets the unique needs of their patient population while also maximizing their resources.

Fitch, M.I., Porter, H.B., \& Page, B.D. (2008). Supportive Care Framework: A Foundation for Person-Centered Care. Pembroke, ON: Pappin Communications.

Fitch, M.I., \& Steele, R. (2010a). Identifying supportive care needs of women with ovarian cancer. Canadian Oncology Nursing Journal, 20(2), 66-74.

Fitch, M.I., \& Steele, R. (2010b). Supportive care needs of individuals with lung cancer. Canadian Oncology Nursing Journal, 20(1), 1522.

Hutton, J., Martin, L., Field, C.J., Wismer, W.V., Bruera, E.D., Watanabe, S.M., et al. (2006). Dietary patterns in patients with advanced cancer: Implications for anorexia-cachexia therapy. American Journal of Clinical Nutrition, 84(5), 1163-1170.

Kennett, C., \& Payne, M. (2005). Understanding why palliative care patients 'like day care' and 'getting out'. Journal of Palliative Care, 21(4), 292-298.

Kirkbride, P. (1995). The role of radiation therapy in palliative care. Journal of Palliative Care, 11(1), 19-26.

Sarna, L., Evangelista, L., Tashkin, D., Padilla, G., Holmes, C., Brecht, M., et al. (2004). Impact of respiratory symptoms and pulmonary function on quality of life of long-term survivors of non-small cell lung cancer. Chest, 125(2), 439-445.

Sarna, L., Lindsey, A.M., Dean, H., Brecht, M.L., \& McCorkle, R. (1994). Weight change and lung cancer: Relationships with symptom distress, functional status and smoking. Research in Nursing \& Health, 17(5), 371-379.

Solano, J., \& Higginson, I. (2006). A comparison of symptom prevalence in far advanced cancer, AIDS, heart disease, chronic obstructive pulmonary disease and renal disease. Journal of Pain and Symptom Management, 31(1), 58-68.

Steele, R., Fitch, M.I., Alderson, D., Barrow, K., Hurst, N., \& Doyle, C. (2004). Measuring supportive care needs of women with gynecological cancer. Supportive Care in Cancer, 12(6), 411.

Steele, R., \& Fitch, M.I. (2008). Why patients with lung cancer do not want help with some needs. Supportive Care in Cancer, 16(3), 251-259.

Voogt, E., van der Heide, A., van Leeuwen, A.F., Visser, A.P., Cleiren, M.P., Passchier, J., et al (2005). Positive and negative affect after diagnosis of advanced cancer. Psychooncology, 14(4), 262-273.

Whelan, T.J., Mohide, E.S., Willan, A.R., Arnold, A., Tew, A., Sellick, S., et al. (1997). The supportive care needs of newly diagnosed cancer patients attending a regional cancer centre. Cancer, 80(8), 1518-1524. 